\title{
Estado-providência: chega de odes e críticas neoliberais
}

\section{The Welfare State: no more odes and criticism}

\author{
Robson de Oliveira \\ Doutorando do Programa de Pós-Graduação em Serviço Social pela \\ Universidade Federal de Santa Catarina, Florianópolis (SC), Brasil. \\ robbit86@gmail.com
}

\begin{abstract}
Simone Sobral Sampaio
Doutora em Serviço Social pela Universidade Federal do Rio de Janeiro — UFRJ e pós-doutora pela Universidade de Paris, professora do Departamento de Serviço Social e do Programa de Pós-Graduação em Serviço Social da Universidade Federal de Santa Catarina, Florianópolis (SC), Brasil.
\end{abstract}

simone.s@ufsc.br

Resumo: O objetivo deste texto é analisar os mecanismos e operacionalização do Estado-providência em sua produção de certo tipo de "servilismo cidadão", por via da capitalização dos interstícios mais cotidianos e globais da vida dos indivíduos na sociedade capitalista. $\mathrm{O}$ texto demonstra ainda a forma como o neoliberalismo acaba por obliterar essa proposta ao presumir, enquanto regime de veridição para a gestão da seguridade social, o mercado como ente definidor do campo de intervenção da política social e a vinculação entre moral do trabalho e pobreza no acesso aos direitos sociais.

Palavras-chave: Estado-providência. Neoliberalismo. Seguridade social
Abstract: This text aims at analyzing the mechanisms and operationalization of the welfare state in its production of a certain kind of "citizen servility" by the capitalization of the most daily and global interstices in the individuals' lives in the capitalist society. It also shows the way neoliberalism ultimately obliterates such a proposal when, as a veridiction regime for the management of social security, it assumes the market is a defining entity of the social policy intervention field and the linking between work ethic and poverty in the access to social rights.

Keywords: Welfare state. Neoliberalism. Social security. 


\section{Introdução}

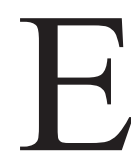

m 2016 o livro chamado L'État providence completa trinta anos de sua publicação. Essa lembrança justifica-se não apenas pelo fato de ter provocado distintas influências no campo das profissões. Lê-lo de novo é observar em retro/perspectiva a construção da legitimidade do Estado - não importa a que fins, os neoliberais que o digam. Lê-lo é conhecer a fina maquinaria de produção do servilismo da cidadania, esse entorpecimento ofertado como se fosse o fim da nossa sociabilidade e, ao mesmo tempo, seu processo contínuo na construção de um elemento igualmente palatável ao neoliberalismo, qual seja, o risco social.

O presente texto ocupa-se da análise do Estado-providência inferindo-o a partir das positividades capazes para o seu nascimento e seu funcionamento - daí a utilização do livro L'État providence de François Ewald — na tentativa de sua compreensão interna não para desqualificá-lo, ao sabor das teorias liberais, nem para entronizá-lo, como padrão de modelo estatal que se sustenta como forjador de direitos sociais e democráticos, ou de caminho "pacífico" para outra sociedade; mas para entender seus mecanismos e a sua operacionalização no quadro do longo processo de assujeitamento e governamentalização da vida dos indivíduos na sociedade capitalista.

\section{Desenvolvimento}

No livro L'État providence tem-se a problematização do "acidente" no quadro de formação do Estado-providência ${ }^{1}$ e do nascimento da Seguridade Social como a socialização das responsabilidades. Responsabilidades no seu par com a solidariedade e o acidente, não como um tipo de acontecimento, mas, como relação com o outro, como problema social.

1. François Ewald faz sua genealogia a partir da lei de 9 de abril de 1898 sobre a responsabilidade dos acidentes de trabalho, que elabora a categoria de risco. E, também, seu estudo percorre desde a promulgação do Código Civil francês em 1804. Durante esse período, a categoria de risco era refletida como uma das experiências morais do Ocidente. 
O acidente possui regularidade, previsibilidade, é calculável. Sua objetividade encontra-se na sua produção na vida coletiva/social, e não em uma falha individual (na relação com a máquina ou a técnica) ou na relação com a natureza (catástrofes, tempestades). Nesse sentido, o acidente é tomado como um mal social, e não produto de uma conduta imprópria ou isolada. Como mal social, comprova a característica dos indivíduos em suas relações de solidariedade e interdependência com a presença do risco. O mal social representaria o preço a ser pago pelo progresso, em que todos (e não cada um) são responsáveis pelo bem comum.

A existência do risco social reinscreve as obrigações de cada um e necessita de regulação e técnicas da ordem da seguridade. "O risco é a categoria-base das políticas de solidariedade, a categoria fundamental da nova moral. O risco testemunha o fato que nós vivemos em sociedade"2 (Ewald, 1986, p. 371). ${ }^{3}$ Nestes termos, a sociedade como sujeito jurídico-sociológico de obrigações ao mesmo tempo em que deve tudo, pode tudo. A garantia dos direitos (à vida, a ser beneficiário) confere à sociedade o direito de assujeitar os indivíduos a obrigações coletivas. $\mathrm{O}$ direito e sua jurisprudência não atuando somente na ordem da punição, mas de forma preventiva e prescritiva: o que se deve fazer. Nesse quadro social, "a moral absorve o direito e se confunde com a política” (p. 22). No Estado repousa a vida civil, o qual regula a vida de cada um nas esferas pública e privada.

$\mathrm{O}$ acidente de trabalho, emblemático para se pensar o risco social, representava na ordem liberal a incompatibilidade entre o político e o jurídico. A responsabilidade pelo risco social, longe de ser uma tentativa de regulação, acentuava os conflitos entre trabalhadores e patronato na medida em que o segundo era responsabilizado pelo acidente. ${ }^{4}$ Mas em outra racionalidade e em um longo processo de reforma, o acidente, como mal social e objetivação

2. Todas as citações da obra de Ewald (1986) foram traduzidas pelos autores do presente texto.

3. A partir daqui, em todas as citações desse autor, deixaremos apenas o número da página entre parênteses, uma vez que todas se referem à mesma obra.

4. Porém sabe-se que, se não existe risco sem seguro, atribuir aos chefes das empresas sua responsabilidade é uma ficção: pois que é transferido para as instituições de seguro, em outras palavras, para o próprio consumidor ou, ainda, ao cidadão. 
da sociedade, tem sua responsabilidade socializada. A epistemologia ditada por essa nova racionalidade do poder entendia o todo não como dependendo de suas partes ou como produto delas, mas como fundador das partes e aquele que lhe dá inteligibilidade. Nesse quadro, os próprios indivíduos são resultado de um processo de individualização e "como partes do todo obedecem as suas leis e contribuem para sua ordem" (p. 350). E nesse processo o direito social joga um papel importante como um novo modo de gestão das responsabilidades.

No direito social, a competência jurídica pertence a todos os indivíduos como direito à vida. $\mathrm{O}$ valor fundamental é a vida, e não a liberdade. A vida humana, com suas potencialidades, torna-se o capital mais precioso que não deve ser ameaçado por ninguém, sendo confiada "a uma instância totalizante o poder exorbitante de decidir em nome de todos o que é o bem de cada um” (p. 25). Nessa processualidade, o dever social comparece numa relação de anterioridade e contrapartida do direito social.

Encontra-se, então, uma nova economia jurídica de direitos e obrigações sociais, sendo a totalidade dos sujeitos credores e devedores ao mesmo tempo, em outro esquema de solidariedade, baseado na responsabilidade como repartição dos riscos, diferente da liberal ${ }^{5}$ (repartição-falta).

Torna-se necessário harmonizar a vida moderna prenha de riscos, em que os danos, os prejuízos e as perdas são tidos como normais. No cometimento de uma falta, a pergunta desloca-se do "quem a cometeu" (falta) para "a quem o dano deve ser imputado" (risco), a partir não de preceitos morais, mas de regras - sempre móveis — de equidade social. A sociedade é quem deverá julgar a responsabilidade do dano. A responsabilidade como decorrente da sociedade de risco, e não como condição natural de indivíduos livres.

A seguridade como tecnologia jurídica, nascente no final do século XIX, inaugura um novo regime do direito: se quer preventiva e não punitiva, técnica na racionalidade da socialização dos prejuízos baseados nos princípios

5. No modelo liberal, a moral sendo o campo das obrigações positivas de fazer o bem a outro encontra-se desligada do direito. Se o direito pode limitar ou coibir uma ação que prejudique outra pessoa, este não poderia obrigar ninguém a fazer o bem ou reparar o erro feito por outrem. 
de solidariedade. Mas a que o ideário presente nessa concepção se opunha? Ewald (p. 358) explica: “O solidarismo seria assim um modo de solução de terceira via entre o liberalismo e o socialismo; uma dessas vãs tentativas de conciliar os contrários, a maneira pela qual a burguesia da belle époque teria encontrado para se salvar do perigo operário".

Embora ainda se tratando de uma questão moral, esta não está ligada à religião. Trata-se de uma moral laica que absorve o direito num regime de obrigações positivas de uns em relação aos outros. ${ }^{6}$

O mal social, não como algo natural e nem como algo próprio do indivíduo, estabelece-se na relação social — assim como na moral social —, em que onde o bem-estar de cada um está ligado ao bem-estar de todos. À primeira vista, parece o fim de todos os egoísmos. Mas não é nada disso. Trata-se do cuidado, da vigilância e do controle que deve ser feito na vida de cada um em nome da prevenção do mal, que é sempre múltiplo na diversidade de suas causas. Essa multiplicidade exige inúmeras instituições, diversas em suas funções, atuando em nome do bem-estar social, e não somente o Estado reunindo em si todos os poderes.

Nesse caso, direitos e deveres fundem-se e devem ser ambos respeitados por todos. Indivíduos, absolutamente, como seres sociais: são socialmente individualizantes, produto social e só existem como seres sociais. Potencialidades e capital humano sendo forjados no processo social, na "totalidade social". Indivíduos-membros que devem ser desenvolvidos e socializados conscientes dessa dependência social.

Essa dependência ontológica reclamaria por uma igual proporção entre vantagens e obrigações sociais, uma outra ideia de justiça. Regras mútuas e contratuais consultadas e consentidas, que partem do princípio de que todos têm consciência da dependência comum, reconhecem-se como iguais e, assim, não podem ter mais direitos que outros. E, finalmente, que as regras são móveis e não definitivas, mas fruto de uma negociação permanente, sendo necessária a liberdade de expressão.

6. E. Durkheim (1978) afirma, na divisão social do trabalho, que nosso primeiro dever, é de nos fazer uma moral. 
É nesse conjunto de modificações ocorridas na prática das obrigações que se produziu a socialização da responsabilidade, a formação do direito social e um processo extenso de securitização das relações sociais. Essa sociedade de solidariedade ou de seguridade instaura uma outra racionalidade política, a positividade política do Estado-providência. Esse tipo de Estado proporciona o desenvolvimento da industrialização que já conta com uma mão de obra constituída, socializando seus riscos, de modo a promover a integração social da indústria em benefício da "sociedade".

Esse modelo estatal reforça o deslocamento da assistência da zona religiosa e moral (beneficência, caridade, piedade) para a esfera do direito social, sendo necessário gerir a vida dos indivíduos de forma preventiva, visto que cada um é fator de risco para o outro na relação social, de forma que todos possam realizar suas potencialidades.

A racionalidade do Estado-providência, na sua ilusão de conciliar as contradições, implementa a normalização dos comportamentos ameaçando a liberdade. Mas, segundo Ewald, essa tendência pode ser evitada: no lugar da centralização das instituições, alvo fácil de manipulações políticas, descentralização; outro limite seria o que o autor chama de psicológico, ou seja, a busca de extração máxima de benefícios próprios do par garantia-risco; e o terceiro limite seria o fato de que essa é uma relação jurídica, contratual, que implica direitos por parte do segurado que não pode ser cobrado além do consentido.

Esquecendo o que chamou de "tentações totalitárias", Ewald (p. 529) enaltece o Estado-providência:

Longe de absorver o todo da vida das pessoas, a seguridade permite, ao contrário, a cada um conduzir sua vida individualmente. A seguridade dá uma solução inédita ao problema político [...]: combinar liberdade e solidariedade, socialização e individualização; formar um todo sem que isso se faça em detrimento das partes. A seguridade é uma das formas práticas dessa combinação. Ela é uma forma política que permite garantir um maximum de liberdade individual em um mundo cada vez mais solidário e socializado. 
Pode-se, pois, afirmar que três grandes deslocamentos caracterizam o nascimento das sociedades de seguridade: a espacialização, a ligação social materializada na trama jurídica e a racionalidade econômica investida de uma racionalidade técnica. Respectivamente, resultam em uma nova gestão do espaço social que cria novos tipos de assujeitamento, regulam os problemas da associação política através de soluções jurídicas positivas, inflacionando o campo jurídico; e, a delimitação do poder político que pode ser controlado pelo Estado (equilíbrio entre centralização e descentralização, gestão pública e privada).

Através de uma análise positiva do Estado-providência, e não uma análise comparativa desse modelo, quer com o liberalismo ou com o socialismo, Ewald aponta que nesse tipo de Estado os valores são sempre cambiantes, mutáveis, resultado de conflitos e negociações contínuas, em que a liberdade não é letra morta, e sim comprovada nessa relação social de instabilidade. Nesse caso, a liberdade é ameaçada quando o processo de correlação de forças estagna-se com uma posição "vencedora". Paradoxalmente, é a estabilidade daquela correlação que ameaça o Estado-providência.

Por outro lado, é o seu contrário — a instabilidade — que torna complexa a regulação promovida pelo Estado-providência. Nesse caso, entende-se por regulação

Os mecanismos graças aos quais a relação do todo e de suas partes, e das partes entre elas, se encontra constantemente ajustada por regras bastante flexíveis que permitem ao conjunto social permanecer aberto para que cada um possa encontrar uma identidade e uma regra de conduta conveniente, em uma palavra, graças à ordem política-social poderá ser reconhecida como justa para os que nela vivem. (p. 533; grifos do autor)

O que se pode perceber é a predominância da ideia de justiça social nessa racionalidade política que "deveria ultrapassar, corrigir, decidir a lógica da economia” (p. 533). Concepção de justiça que não seria somente crítica à determinada ordem social, mas teria um conceito positivo. 
Repensar a curta duração desse tipo de experiência finalizada, grosso modo, pela política neoliberal significa questioná-la internamente. Colocar a questão do financiamento como seu único algoz seria apressado demais. Segundo Ewald, o principal seria a crise dos próprios valores que sustentam o Estado-providência. O consenso em torno da igualdade, do bem-estar, da seguridade, da redistribuição e repartição são abalados para além de suas técnicas e do montante de cada contribuição.

Esse consenso pode retornar a partir — segundo Ewald — de uma tripla invenção democrática: representação, descentralização e que os atores sejam qualificados como sujeitos do social (p. 547). O autor "resolve" a crise do Estado-providência sem melhor precisar cada um desses aspectos, deixando margem para uma interpretação ou saída individualista.

$\mathrm{Na}$ questão da representação, afirma que tanto as de tipo parlamentar como as sindicais são insuficientes. Seria preciso então forjar novos tipos de representação. O próprio autor reconhece a descentralização - em que as escolhas poderiam ser formuladas respeitando as especificidades locais como problemática devido a questões como a da unidade nacional e da igualdade, daí a necessidade de obedecerem alguns limites (que não são apontados por ele). Quanto ao terceiro aspecto — que os atores sejam qualificados como sujeitos do social — condição anterior à viabilização das demais —, faz-se necessário a transparência institucional para o seu devido controle e fiscalização. Mas aqui tem-se outro problema. Segundo Ewald, o conhecimento por todos do custo da Seguridade Social e, ainda, das cotas pagas por cada um levaria ao fato de alguns sentirem-se sobrecarregados nessa manutenção (por exemplo, os mais jovens em relação à população idosa). E seria preciso que essa transparência viesse justificada em um quadro fornecido por regras justas.

Tirando a representação, os dois aspectos sofrem objeções do próprio autor que as indicou. Sendo que a terceira, a mais importante, mostraria o "paradoxo da solidariedade", pois esta exige "obscuridade, ignorância" (p.548). Parece que as saídas apontadas não combinam com a gestão do Estado-providência. Porém essa invenção democrática proposta seria o caminho para se pensar outra cidadania que não a de deficientes cívicos. 
Aqui encontra-se um problema não só da análise do autor, ou melhor, do quanto este rende-se à anulação do sujeito, quanto dos próprios limites do Estado-providência quando credencia um único ator (o Estado) para geri-lo e operacionalizá-lo, inventando um aparente consenso ou administrando interesses corporativos.

Talvez seja no par solidariedade-justiça que se inscreveria a crise do Estado-providência. Quer dizer, conformar práticas de solidariedade com justiça social, sem definir esta última, deixaria a solidariedade num campo frágil das iniciativas individuais, bem ao sabor da política neoliberal.

Amparando-se na definição aristotélica de justiça social "como arte específica de distribuição e repartições”, Ewald reafirma que o Estado-providência “designara uma positividade política própria” (p. 552). Essa concepção de justiça social compõe-se de três fatores interligados: igualdade, medida comum e reciprocidade.

A igualdade não seria da ordem da imposição, mas uma "maneira de estabelecer uma relação de igualdade entre coisas comuns" (Idem) e a combinação entre coisas desiguais a partir de uma relação de equivalência. ${ }^{7}$ Mas qual seria a medida comum para estabelecer essa equivalência? Como determinar o valor de todos os valores na definição de um equivalente geral? A noção de reciprocidade seria a regra de justiça que tornaria possível que os indivíduos vivam em uma comunidade de direito, e não em uma sociedade conflituosa e guerreira.

Mas, ainda assim, restaria responder sobre o equivalente geral, já que este não repousa mais nem na igualdade fundada na natureza e nem na noção de bem comum. É aí que Ewald apresenta a norma como "um puro instrumento de comparação, uma medida que a sociedade dá a ela mesma para acompanhar suas próprias transformações, e que, lá está o ponto, se transforma com as transformações que ela descreve" (p. 583). Nesse quadro, o indivíduo normalizado é descrito com uma excessiva condescendência:

7. Ewald (1986) atenta que Marx crítica o direito por entender que este não pode satisfazer a justiça porque é incapaz de respeitar o fato das desigualdades. 
O sujeito é por sua vez constituído como objeto de uma observação perpétua, objeto de exame, submetido a um trabalho permanente de individualização. E, correlativamente, a norma propõe ao sujeito diferenciado uma maneira de fazer valer sua relação com os outros sob a forma de uma insaciável reivindicação de igualdade. (p. 584)

Conforme Ewald, a norma possibilita que cada um pense sua identidade e seu lugar na sociedade, faz com que cada um seja alguém para o outro de modo a socializar as identidades, os julgamentos e definir o consenso, é a "forma moderna da ligação social" (p. 584; grifos do autor). A norma descreveria uma hegemonia no quadro da correlação de forças, sempre relativa ou temporal. Seria, nas palavras do autor, "um princípio de totalização sem universal", "o princípio de equilíbrio". Trata-se de um procedimento: a forma de regulação do conflito sem exterminá-lo. Um modo de subjetivação que toma a forma de participação, em que a sociedade é a medida de todas as coisas. Sua adoção não depende do fato de ser verídica, e sim quando é aderida como opinião, como parte da "consciência coletiva" (importante destacar o papel da mídia). A ordem da norma não é social ou econômica, mas da política pura.

Assim, o autor tenta afastar a hipótese de uma crise do Estado-providência não porque comprova a sua inexistência, mas porque absorve a crise no movimento de instabilidade desse Estado que vive numa reforma permanente: "não podendo mais nos acordar sobre uma medida comum, nós somos condenados à 'crise', como a forma normal da vida política” (p. 604).

\section{0 neoliberalismo contra o Estado-providência}

Porém a história já cuidou de comprovar que esse modelo estatal chegou a seu termo. Os ajustes neoliberais atacaram o complexo da Seguridade Social com, pelo menos, três armas ou argumentos.

$\mathrm{Na}$ governamentalidade neoliberal é preciso fazer a partilha entre o que cabe ao campo da moral e o que se restringe ao direito. Restabelece na 
discussão sobre o direito à seguridade a oposição do que cabe à solidariedade e o que deve, juridicamente, à seguridade. Outra polêmica, reconduzida pelo neoliberalismo, é a medida de repartição entre salário direto e indireto, quer dizer, definir a proporção que deverá ser recolhida e redistribuída. E, ainda, o ataque operado pelo neoliberalismo concentra-se na ideia de limitar o acesso à seguridade, no qual o social é, claramente, subordinado ao econômico. Mais que isso, no neoliberalismo o mercado é vetor de veridição, definindo todo o campo da política social e a sua pertinência.

Nesses termos, o problema do limite é o que está sendo definido em detrimento do igual acesso de todos à seguridade, pois que o acesso infinito de cada um vincula-se ao número de prestações que é capaz de pagar, reinaugurando um grande problema sobre quem será o árbitro e quais serão as medidas (flexíveis, ágeis, sempre provisórias) utilizadas para determinar o limite de acesso à seguridade. Esses problemas reconduzidos pelo neoliberalismo têm uma quarta dimensão: a ética do trabalho.

O que é ameaçador para o atual sistema de produção é a vinculação entre proteção social e trabalho, em outras palavras, a garantia do bem-estar social sem o imperativo do trabalho, como se isso fosse possível nos marcos do capitalismo. No neoliberalismo, a atenção aos necessitados deve observar que essa prática não representa um desestímulo ao trabalho ou, ainda, uma diminuição da disposição individual ao trabalho.

A ideologia neoliberal diz "propiciai direitos aos pobres e tereis mais pobres", construindo uma perversa ideia de que um sistema de proteção social em si reforça um comportamento de dependência. Os conservadores temem que esse sistema seja um incentivo irresistível para os que já estão no mercado e que recebem baixos salários (ou os que querem/precisam entrar) abandonem seus postos de trabalho e reivindiquem serem beneficiários do aparato de Seguridade Social público.

Dessa forma, a origem da pobreza é remetida para a esfera moral. Nesse caso, o pobre é aquele que não acertou na vida, sua pobreza é fruto de sua incapacidade pessoal para progredir ou então fruto da preguiça. De questão econômico-política, a pobreza volta para a zona da falta e do erro. O discurso 
dominante afirma que o indivíduo deve suprir suas necessidades, primeiramente, através do mercado. Caso isso não ocorra, graças a suas debilidades pessoais, cada um deve socorrer-se via ajuda de familiares e da comunidade. A boa ação retorna ao espetáculo. Mas, principalmente, socorrer-se é o imperativo moral e social da governamentalidade neoliberal que aposta não na securitização do indivíduo, mas no aprofundamento da sua mercantilização.

Diante disso volta a questão: além dos custos econômicos, dos gastos sociais que ameaçam os donos do capital, outro problema mais profundo e radical à ordem capitalista encontra-se na necessidade do trabalho.

Marx (1985, p. 157) já havia afirmado que

A constante manutenção e reprodução da classe trabalhadora permanece condição constante para a reprodução do capital. O capitalista pode deixar tranquilamente seu preenchimento a cargo do impulso de autopreservação e procriação dos trabalhadores. Ele apenas cuida de manter o consumo individual deles o mais possível nos limites do necessário.

Ao mesmo tempo, pode-se questionar a submissão dos trabalhadores promovidos pelos donos do capital quando prolongam seu assujeitamento através da exigência que desempregados procurem empregos que não existem mais. A oferta neoliberal é o prolongamento disso no investimento feito por cada um para se tornar empregável ou, ainda, tornando-se capital humano.

\section{Considerações finais}

No quadro da seguridade, o risco é uma forma de tratar alguns acontecimentos que podem acometer uma população. A ideia de risco substitui o que antes era tido como um golpe de sorte ou azar que se deveria suportar. $\mathrm{O}$ que poderia ser um acontecimento restrito à vida privada ganha objetividade e objetivação em uma tabela estatística. $\mathrm{O}$ risco está enredado pela sua factualidade e verificação, é calculável e coletivo; em uma palavra: social. 
Ewald "esquece" na sua história da positividade do Estado-providência que o processo de individualização nele ocorrido produz subjetividades: medianizar, normalizar, quantificar é a gestão da população operada por esse Estado. A ficção do homem médio seria a meta. É essa individualidade média que rege a probabilidade de risco para cada um, mas o fato primeiro é que todos representam um fator de risco para o outro e vice-versa. $\mathrm{O}$ indivíduo social, no Estado-providência, é ao mesmo tempo fator de risco e sujeito a ele.

O risco como a nova forma de ligação social autoriza a busca incessante por um controle da população que deverá ser vigiada, obervada, quantificada e qualificada através de eternos recenseamentos. Esse inventário sobre a população é capaz de mostrar desvios e diferenças, distinções e semelhanças.

A sociedade da seguridade realiza a repartição da responsabilidade por um dano cometido sobre um patamar de regras de justiça ou de direito que são fixadas socialmente, no qual o Estado e seu aparato institucional não reduzem a segurança a um órgão, mas ele é todo concebido a partir da ideia de segurança.

A insistência de Ewald em apresentar o Estado-providência como um Estado não totalitário revela que sua análise não é apenas uma exposição das positividades do nascimento e do funcionamento desse tipo estatal, mas termina por apresentar-se como uma defesa de um modelo jurídico e de gestão governamental. Sua defesa responde à acusação liberal que prega o direito como garantia contra o poder do Estado e seus excessos, um direito político mais que social. E, ao mesmo tempo, "equaciona" a contradição entre as classes sociais, em nome dos direitos e de uma harmoniosa vida em sociedade.

A necessidade de direitos sociais é inegável, mas como conjugá-los em um sistema inflacionado juridicamente como nas sociedades do Estado-providência? A cada novo direito, ou antecedendo-lhe, tem-se novos deveres, lembrando a terminologia do homem endividado de que fala Deleuze (2000). Certamente Ewald sabe disso, mas as conclusões ou consequências políticas para a reversão do quadro não são apontadas. O autor e o seu ode ao Estado-providência pregam sua perpetuação. Sobre o livro L'État providence, de 
François Ewald, podemos lembrar as críticas de Adorno ao livro Admirável mundo novo: "Huxley critica o espírito do positivismo. Entretanto, como até mesmo esta crítica se atém aos choques, às imediaticidades vivenciadas, registrando sem maiores questionamentos a aparência social como fato, Huxley torna-se um positivista"8 (Adorno, 1983, p. 114; tradução livre).

O Estado moderno em sua relação com a "população" requisita o pacto da seguridade. O Estado garante à população que esta será protegida não apenas em nome de suas fronteiras — demarcando sua territorialidade mas, principalmente, contra o risco, o prejuízo e toda forma de acidente. $\mathrm{O}$ Estado intervém através de um controle rigoroso da trama cotidiana. Esse formato corresponde à racionalidade política do Estado-providência na medida em que controla tudo, todos os aspectos da vida da população. Por outro lado, seria errôneo afirmá-lo totalitário, no sentido estrito do termo, visto que existe a pluralidade de partidos políticos, um regime democrático. Mas ainda cabe a pergunta: pode-se dizer que o Estado-providência seja totalitário por agir arbitrariamente nos acontecimentos que ele mesmo julga como perigosos? Trata-se de uma intervenção sutil e habilidosa muito mais tolerada. Um Estado que dispensa a rigidez própria dos regimes totalitários e adota uma postura flexível e ágil, que precisa ser analisada para saber até que ponto as pessoas pagam o preço da segurança.

O comportamento do Estado-providência parece justificado porque a necessidade de seguridade é admitida pela população. Essa população vai ser, ao mesmo tempo, sujeito de necessidade e objeto do governo, no alcance de suas medidas e na definição e normalização da vida de cada um.

Nesse caso, antes de afirmar que se trata da estatização da vida — termo longe de ser anacrônico para os dias de hoje — , não seria equivocado afirmar que a crise e a morte do Estado-providência deixaram como herança a governamentalização da vida ou o assujeitamento do indivíduo pelos poderes políticos exercidos pelo governo.

8. No original: "Huxley criticizes the positivistic spirit. But becase his criticisme confines itself to schocks, while remaining immersed in the immediacy of experience and merely registering social illusions as facts, Huxley himself becomes a positivist". 
Assim, vale voltar a Ewald, pois se o Estado-providência chegou ao seu final, sua história não terminou de todo: "nós estamos na idade do que se poderia chamar de "sociedade de seguridade", e o autor atenta que essas não seriam somente as sociedades em que "multiplicam-se as instituições de seguridade, ainda que isso não seja sem importância nem sem significação, mas sobretudo sociedades que refletem seus problemas e imaginam sua regulação através da técnica e das categorias da seguridade” (p. 20).

É justamente contra as técnicas de normalização e individualização do Estado que é necessário lutar. Os direitos sociais não são absolutos; situam-se num campo móvel. Por mais fundamentais que sejam, são direitos históricos que dependem do grau de pressão política dos sujeitos envolvidos. E, ainda, um processo de democratização da vida política, social e econômica, que reconhece diferentes atores coletivos sem amparar-se no corporativismo. ${ }^{9}$ A constituição dos direitos sociais e a estrutura de proteção social situam-se no terreno minado e conflitivo da correlação de forças de classes antagônicas, em que as demandas dos diferentes atores sociais recolocam a questão política entre direitos sociais, democracia e economia.

Desde os primeiros direitos promulgados pelas Constituições burguesas, analisados por Marx (1991), explicita-se um terreno fraturado entre a política e o indivíduo privado. Redimir este no campo da solidariedade política na partilha da seguridade com certeza não teria vida longa, pois que direitos sociais, assumidos socialmente, realizam escolhas indissociáveis de quem nós somos, enquanto sujeitos constituintes da vida social, e não por átomos dispersos na sua própria proteção.

O indivíduo burilado no Estado-providência traz virtualidades também condizentes com o neoliberalismo, na gerência do capital humano. A diferença é como essa gestão se processaria. Se no Estado-providência isso se daria no aprofundamento de sua dependência estatal que justificaria

9. É necessário ir além do tripé Estado-patronato-sindicatos para a definição de outro modelo de bem-estar. E vale lembrar o caso do Parlamento europeu, em Bruxelas, onde multinacionais têm cerca de 10 mil lobistas. 
vigilâncias e controles diversos sobre o seu comportamento e escolhas, no neoliberalismo, diferentemente, o processo se dá através de diversos dispositivos (ideológicos, jurídicos, morais, políticos) que aprofundam a atomização do indivíduo e a vergonha da dependência social. Mas o que essas duas formas e seus conteúdos conservam em comum é a ideia do "outro" como fator de risco, isto é, o indivíduo desregrado que não se compromete com sua autocapitalização.

Porém seria apressado afirmar a necessidade de uma "ideologia social [que] deveria ultrapassar, corrigir, decidir a lógica econômica” (p. 533), nem defender primeiro uma mudança econômica que requalificaria o social. Mas deve-se atentar que esses dois aspectos da vida, somente de forma intrínseca e relacional, constroem novos patamares de civilidade.

Recebido em: 1/2/2016 - Aprovado em: 29/2/2016

\section{Referências bibliográficas}

ADORNO, T. W. Prisms. Massachussets: The MIT Press, 1983. (Studies in Contemporany German Social Thought.)

DELEUZE, G. Conversações. 3. ed. Rio de Janeiro: Editora 34, 2000.

DURKHEIM, E. Da divisão do trabalho social. São Paulo: Abril Cultural, 1978. (Col. Os Pensadores.)

EWALD, F. L'État providence. Paris: Bernard Grasset, 1986.

MARX, K. O capital: crítica da economia política. 2. ed. São Paulo: Nova Cultural, 1985. (Os Economistas, livro primeiro; v. II.) . A questão judaica. 2. ed. São Paulo: Moraes, 1991. 